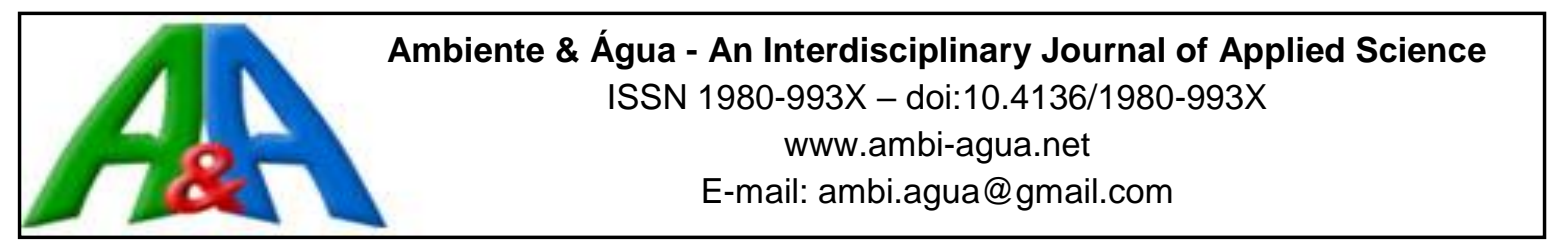

\title{
Avaliação rápida da integridade ecológica em riachos urbanos na bacia do rio Corumbá no Centro-Oeste do Brasil
}

\author{
doi:10.4136/ambi-agua.1857
}

Received: 04 Feb. 2016; Accepted: 11 May 2016

\author{
Giovanna Gomes Cordeiro; Nathália de Macêdo Guedes; \\ Tiago Borges Kisaka*; Gabriela Bielefeld Nardoto \\ Universidade de Brasília (UnB), Brasília, DF, Brasil \\ Departamento de Ecologia \\ *Autor correspondente: e-mail: tiagobk.df@gmail.com, \\ giogomes.2402@gmail.com, nathamacedo@gmail.com, \\ gbnardoto@unb.br
}

\section{RESUMO}

A urbanização tem ocasionado o lançamento de volumes significativos de efluentes domésticos parcialmente tratados nos corpos hídricos brasileiros causando diversos prejuízos ecológicos para estes ecossistemas. Para avaliar a integridade ecológica de riachos na região de Cerrado do Brasil Central foram selecionados quatro pontos de coleta, considerando o nível de influência antrópica ao qual estão submetidos. Foram analisados parâmetros físicos e químicos da água, o uso da paisagem e a comunidade de macroinvetebrados bentônicos. As coletas foram realizadas em julho de 2015 e foram mensuradas "in situ" as variáveis condutividade elétrica, temperatura da água, $\mathrm{pH}$, oxigênio dissolvido, turbidez, largura e comprimento do riacho e velocidade da correnteza. Em seguida, foram coletadas amostras para o seston, perifíton, macroinvertebrados bentônicos e sedimento depositado. O ponto "Referência" apresentou menor abundância de larvas de Chironomus (Chironomidae: Diptera) e maior riqueza taxonômica, além de maior abundância dos grupos taxonômicos Ephemeroptera, Plecoptera e Trichoptera, mostrando ser o sistema mais íntegro dentre os analisados. A sub-bacia delimitada a partir desse ponto mostrou uma maior porcentagem de áreas com vegetação nativa (51\%). Os pontos com presença de efluentes domésticos ("ETE” e "Jusante") por sua vez, apresentaram valores mais elevados de condutividade elétrica, turbidez, maior abundância de larvas de Chironomus e menor riqueza de táxons, mostrando elevado impacto em função das atividades antrópicas. A avaliação rápida realizada com a composição da comunidade bentônica e as variáveis físicas e químicas da água foi suficiente na identificação das alterações na integridade ecológica causadas pela influência antrópica na bacia hidrográfica do rio Corumbá.

Palavras-chave: chironomidae, efluentes domésticos, macroinvertebrados bentônicos.

\section{Rapid assessment of ecological integrity in urban streams of the Corumbá watershed in the Midwest of Brazil}

\begin{abstract}
A major consequence of urbanization in Brazil is the production of large amounts of partially treated domestic effluents dumped into rivers, causing ecological damage to aquatic
\end{abstract}


ecosystems. In order to assess the ecological integrity of urban streams in the Cerrado region of Central Brazil, this study selected four sampling points, based upon the level of human influence to which they are submitted, and the physical and chemical parameters of water, land-use map and benthic macroinvertebrates were analyzed. Samples were collected in July 2015, and electrical conductivity, water temperature, $\mathrm{pH}$, dissolved oxygen, turbidity, stream width and length and current velocity were measured in situ. Samples of seston, periphyton, benthic macroinvertebrates and deposited sediment were collected soon after. The "Reference" sample point showed a lower abundance of Chironomus larvae (Chironomidae: Diptera), and greater taxonomic richness and greater abundance of taxonomic groups Ephemeroptera, Plecoptera and Trichoptera, proving to be the most undamaged ecosystem. The sub-basin delimited to this point showed a higher percentage of remaining native areas (51\%). Sample points where domestic effluents were present ("ETE" and "Jusante") showed higher values of electrical conductivity, turbidity, greater abundance of Chironomus larvae and a low richness, showing high impact due to urban activities. A rapid assessment of the composition of the benthic community and the physical and chemical variables of the water was sufficient to identify the changes in the ecological integrity caused by human influence in the watershed of the Corumbá River.

Keywords: benthic macroinvertebrates, chironomidae, domestic effluents.

\section{INTRODUÇÃO}

Os ecossistemas fornecem "serviços" e benefícios a todos os seres vivos. No caso dos recursos hídricos, o suprimento de água para o abastecimento público pode ser visto como um dos principais serviços proporcionados pelos ecossistemas aquáticos. Tais recursos possuem múltiplos usos nas atividades desempenhadas pelos seres humanos, além de contribuírem com o bem-estar e melhor qualidade de vida da população (Tundisi, 2006).

De acordo com os resultados obtidos por Fonseca et al. (2014), os ecossistemas de água doce do Cerrado parecem levar mais tempo para responder a pressões antrópicas, porém, esta aparente resistência dos riachos pode não ser compensada pela rápida intensificação da interferência do homem através da expansão urbana e o consequente aumento da carga de poluentes orgânicos lançados nos corpos d'água (Fonseca et al., 2014).

Uma das consequências da urbanização é a produção de grandes volumes de esgoto que quando lançados em rios e lagos sem um devido tratamento podem causar diversos prejuízos, não só para a biota aquática, mas também para a saúde humana. O lançamento de efluentes domésticos tem maior impacto em rios de pequeno porte, onde fontes pontuais de poluição podem alterar substancialmente a estrutura e o funcionamento destes ecossistemas (Dodds, 2006).

A integridade biológica de um ambiente aquático é uma medida do nível de conservação das suas condições naturais com o mínimo de influência humana, considerando três importantes componentes: a paisagem (incluindo a preservação da vegetação), a qualidade física e química da água e as suas condições biológicas. Ambientes que se encontram sob o mínimo de influência antrópica são capazes de manter a diversidade de espécies, as quais oferecem diversos serviços ao ambiente aquático. Sendo assim, estes ambientes são considerados áreas de referência, e possuem grande relevância na definição de ações para recuperação da integridade biológica do sistema (Mendonça-Galvão et al., 2011).

Os macroinvertebrados possuem uma ampla variedade de funções nas cadeias tróficas em ambientes aquáticos, dentre as quais destacam-se a sua capacidade de acelerar os processos de decomposição e consequentemente a liberação de nutrientes através da coluna d'água. Dessa forma, desempenham importante papel na transferência de energia no ecossistema, além de 
constituírem um grupo muito diverso (Merrit et al., 2008).

Sendo assim, estudos têm sido desenvolvidos com macroinvertebrados para a avaliação de ambientes aquáticos no Brasil (Oliveira et al., 2010; Machado et al., 2015). Esses organismos podem acompanhar o gradiente de impacto antrópico, refletindo diversas relações físicas, químicas e biológicas com o meio, permitindo assim que eles sejam excelentes indicadores da integridade do ecossistema (Allan e Castilllo, 2007; Merrit et al., 2008). As larvas de Chironomus (Chironomidae: Diptera), por exemplo, são abundantemente encontradas em ambientes impactados por esgoto (Oliveira et al., 2010; Machado et al., 2015), sendo capazes de viver em ausência completa de oxigênio por horas, e são consideradas "coletoras" se alimentando principalmente de matéria orgânica (Merrit et al., 2008).

Nesse contexto, este trabalho teve como objetivo avaliar a integridade ecológica de riachos pertencentes a uma bacia hidrográfica cuja paisagem regional sofre influência de atividades antrópicas como a urbanização e a agricultura, além de atuar como corpo receptor de efluentes domésticos parcialmente tratados. Para tanto foram analisadas as variáveis físicas e químicas da água, o uso da paisagem do entorno e a comunidade de macroinvertebrados bentônicos.

\section{MATERIAL E MÉTODOS}

\section{1. Área de Estudo}

A área de estudo localiza-se localiza-se em uma região de cerrado no Distrito Federal (Figura 1A), Brasil, e está inserida na bacia hidrográfica do rio Corumbá (Figura 1B). Esta região é caracterizada por apresentar alta declividade, solos de baixa fertilidade, com deficiência hídrica e pouca cobertura vegetal, o que facilita o processo de erosão e o transporte de sólidos. Os impactos da urbanização na bacia do Corumbá vêm se intensificando devido à expansão das cidades adjacentes, e um dos riscos que estas áreas urbanas apresentam aos recursos hídricos está associado ao fato de estarem localizadas em trechos mais elevados, onde são encontradas as nascentes dos riachos. Os riachos sofrem influência do despejo de efluentes da Estação de Tratamento de Esgoto (ETE) Recanto das Emas, que é tratado a nível secundário, sem a retirada completa de nutrientes e patógenos (CAESB, 2015). Dessa forma, para esta avaliação foi definido um ponto a montante do despejo do efluente (denominado "Montante"). Outros dois pontos foram coletados a jusante da ETE, um abaixo da estação (denominado "ETE"), e outro mais distante, a aproximadamente três quilômetros (denominado "Jusante"). O afluente localizado na área com menor concentração de zonas urbanas e que está inserido dentro da propriedade da Embrapa Hortaliças (Unidade Descentralizada da Empresa Brasileira de Pesquisa Agropecuária-Embrapa), foi denominado "Referência" (Figura 1B).

\subsection{Coleta de dados}

As coletas foram realizadas em julho de 2015. "In situ", foram medidas as variáveis físicas e químicas da água, tais como $\mathrm{pH}$ (pHmetro Digimed), turbidez (Turbidímetro Digimed, em NTU), condutividade elétrica (Condutivímetro marca Digimed, em $\mu \mathrm{S} / \mathrm{cm}$ ), oxigênio dissolvido (Jenway 970 Dissolved Oxygen Meter, em $\mathrm{mg} / \mathrm{L}$ ), temperatura $\left({ }^{\circ} \mathrm{C}\right.$ ) e velocidade da correnteza (medidor de fluxo digital marca FlowWatch, em m/s). Em seguida foram coletadas amostras de seston, perifíton, macroinvertebrados bentônicos e sedimento depositado. O sedimento depositado foi coletado com uma draga do tipo Ekman, em uma profundidade de 5 centímetros no substrato. Os macroinvertebrados bentônicos foram coletados com uma rede em " $D$ " de 0,25 metros de largura e cuja malha possui 250 micrômetros de espessura. A rede foi arrastada ao longo de 1 metro de extensão e 
5 centímetros de profundidade no sedimento, procurando distribuir a coleta de forma proporcional pelos habitats existentes. Somente para algumas Ordens a identificação foi feita até nível de Família. Para tal, utilizou-se um estereoscópio, e os organismos identificados foram contados para obtenção da riqueza taxonômica, da abundância relativa ao total das amostras e da densidade por área amostrada. Para a análise da biomassa de seston, foram coletados aproximadamente 5 litros de água. O perifíton foi coletado em rochas com diâmetros aproximados. As rochas coletadas foram suavemente escovadas e lavadas com jatos de água destilada $(500 \mathrm{~mL})$. Os filtros das amostras de perifíton e seston foram calcinados no fornomufla por 2 horas à $500^{\circ} \mathrm{C}$ para a determinação do teor de matéria seca livre de cinzas. A clorofila-a foi determinada pelo método de extração quente com etanol $90 \%$. O sedimento depositado foi aquecido à $550^{\circ} \mathrm{C}$ no forno-mufla por cinco horas para a análise do teor de matéria seca livre de cinzas. de matéria orgânica. A granulometria do sedimento depositado foi determinada por meio da utilização do agitador de peneiras RO-TAP durante 15 minutos.

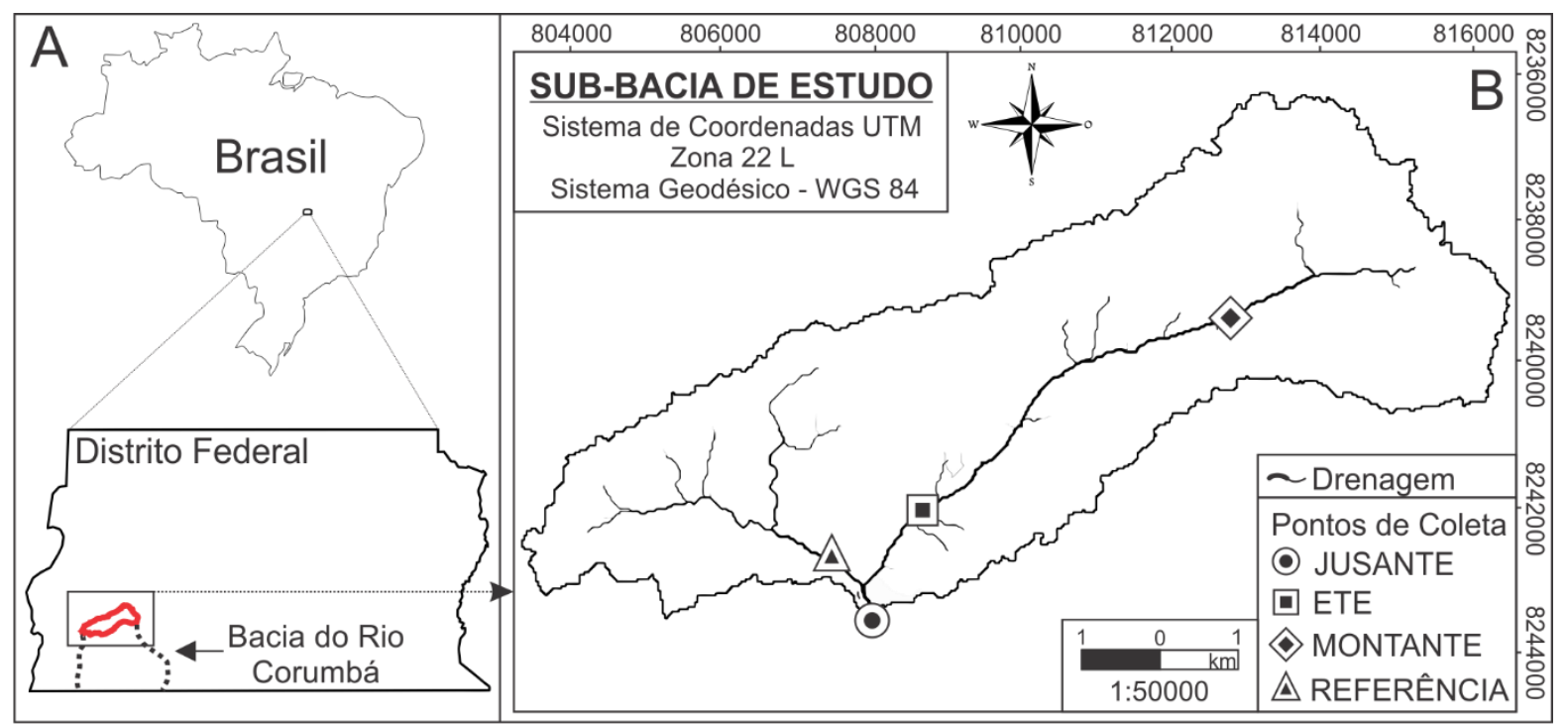

Figura 1. Mapa de localização dos pontos "Jusante", "Referência", "ETE" e "Montante" na bacia hidrográfica do rio Corumbá (B), Distrito Federal, Brasil (A).

Para avaliar os níveis de impactos antrópicos nos riachos selecionados, foi utilizado o Protocolo de Avaliação Rápida da Diversidade de Habitats modificado por Callisto et al. (2002). Os níveis de classificação, adaptados por Fonseca et al. (2014), variam entre "muito impactado" (escore de 0 a 40), "impactado" (escore de 41 a 60), "em transição" (escore de 61 a 80) e "natural" (escore acima de 80 pontos). Primeiramente, para a análise da paisagem, as sub-bacias foram delimitadas por meio do plugin TauDEM (Terrain Analysis Using Digital Elevation Models), considerando os pontos "Jusante" e "Referência". Este procedimento foi realizado para analisar a ocupação na sub-bacia selecionada como referência e na sub-bacia com maior concentração de zonas urbanas. Para a classificação dos usos na paisagem foi utilizado o plugin SCP (Semi-Automatic Classification Plugin). Foi realizada a classificação supervisionada utilizando o algoritmo de máxima verossimilhança e definidos quatro categorias para classificação: Área Nativa, Vegetação Ripária, Agropastoril e Área Urbana. A classe "Área Nativa" agregou as fitofisionomias do bioma Cerrado e a classe "Agropastoril", as atividades agrícola e pecuária bem como áreas com solo exposto. Foram utilizadas imagens do Modelo Digital de Elevação e do satélite Landsat-8 de 2015, adquiridas gratuitamente pelo USGS (United States Geological Surve) Earth Explorer. Ambos os plugins SCP e TauDEM foram utilizados dento do software livre Quantum-GIS. 


\section{RESULTADOS E DISCUSSÃO}

A sub-bacia delimitada considerando o ponto "Referência" como exutório, mostrou ter a maior porcentagem de áreas remanescentes (51\%), tanto para "Vegetação Ripária" (7\%) quanto para "Área Nativa" (44\%). Esta sub-bacia possui como principal atividade antrópica a "Agropastoril". A sub-bacia do rio Corumbá delimitada considerando o ponto de amostragem "Jusante" e desconsiderando a sub-bacia "Referência" possui somente $16 \%$ de áreas remanescentes e a classe de uso predominante é a "Área Urbana" (Figura 2).

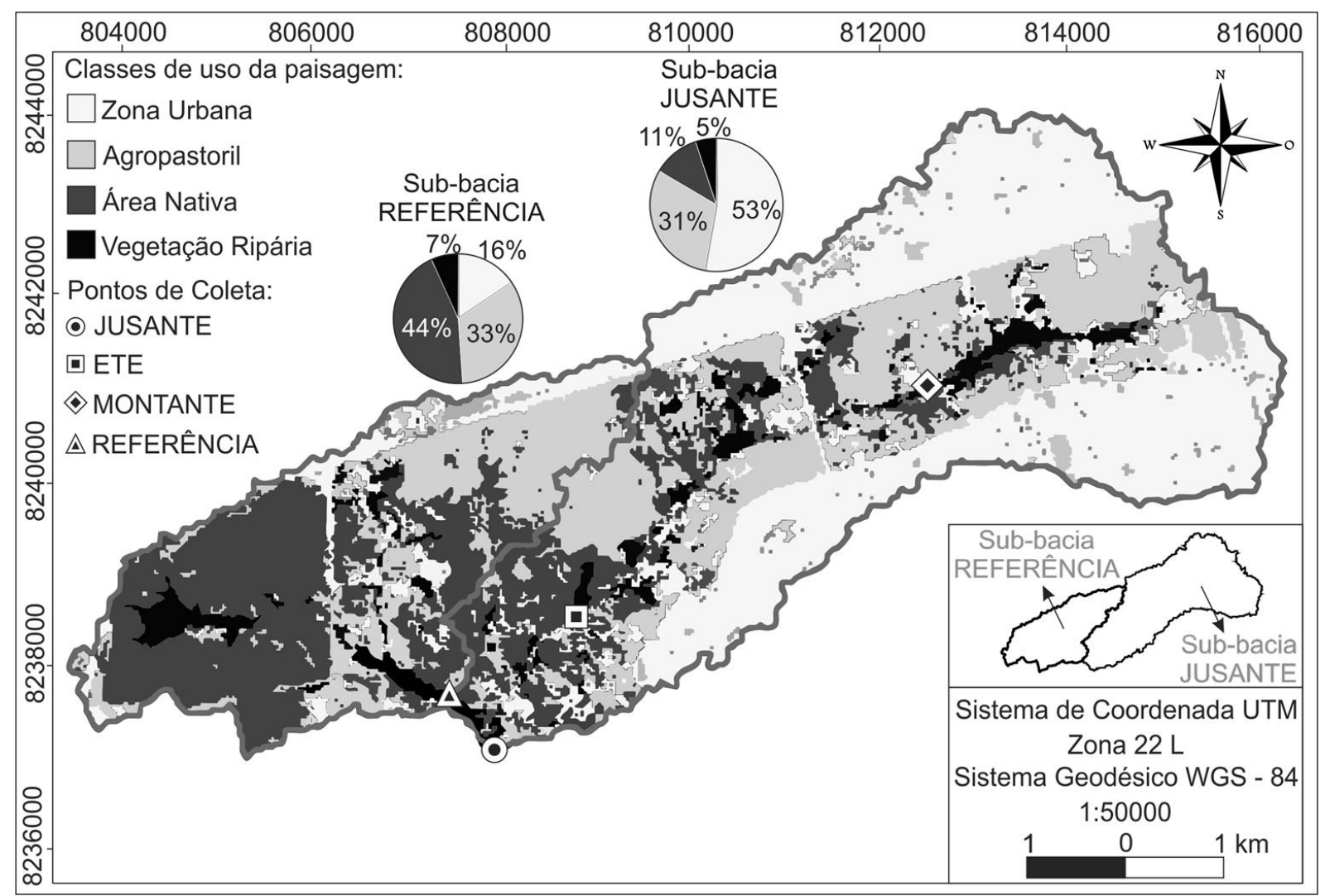

Figura 2. Resultado da classificação supervisionada gerada a partir de uma imagem Landsat-8 considerando os pontos "Referência" e "Jusante" para o cálculo dos limites de drenagem das subbacias.

A pontuação final do Protocolo de Avaliação Rápida de Hábitat classificou o ponto "Referência" como "natural". Já o ponto "Montante" foi classificado como "impactado" e os pontos "ETE" e "Jusante" como "muito impactados", principalmente em função da presença de efluentes domésticos e pelo nível de degradação da vegetação ripária e do solo ao longo do riacho.

As variáveis turbidez e condutividade elétrica apresentaram os maiores valores nos pontos "ETE" e "Jusante", o que pode estar associado ao lançamento de efluentes pela Estação de Tratamento de Esgoto do Recanto das Emas (Tabela 1). Na legislação nacional não há padrões para condutividade em corpos d'água, mas em geral níveis superiores a $100 \mu \mathrm{S} \mathrm{cm}^{-1}$ indicam ambientes impactados (Araujo e Oliveira, 2013). Já as variáveis temperatura e $\mathrm{pH}$ flutuaram dentro da mesma faixa de valores em todos os pontos (Tabela 1). O ponto "Jusante" apresentou baixo valor de oxigênio dissolvido $\left(3,57 \mathrm{mg} \mathrm{L}^{-1}\right)$, podendo indicar a etapa mais tardia do processo de eutrofização do riacho (Dodds, 2006). Sendo assim, o lançamento de efluentes domésticos pode ser apontado como uma das causas da degradação da qualidade da água do riacho receptor. 
Os teores de clorofila-a tanto no seston quanto no perifíton foram baixos no ponto "Referência" (Tabela 1). A ausência de despejo de efluentes domésticos e a baixa ordem do riacho (promoção do sombreamento ripário) podem limitar a produção primária. Os teores de clorofila-a no seston coletado no ponto "Montante" foram próximos ao do ponto "Referência" (Tabela 1), ou seja, tão baixos que o método utilizado não foi capaz de quantificar. Isso pode ocorrer por se tratar de ecossistemas sujeitos as mesmas condições de sombreamento.

Entretanto, os níveis de clorofila-a no perifiton no ponto "Montante" aumentam se comparado com o ponto "Referência". Tal resultado possivelmente se deve ao fato de que a floresta ripária deste ponto já não esteja mais sombreando o riacho em função de sua largura e do impacto gerado nas margens do riacho com as atividades antrópicas. Neste ponto também foi registrado um alto valor de matéria seca livre de cinzas no seston. Tal resultado, aliado com os baixos níveis de condutividade elétrica e clorofila-a no seston observados podem ser indícios de impactos diretos no riacho, como por exemplo a dessedentação animal ou o despejo irregular de resíduos sólidos. O despejo de efluentes domésticos geralmente contém altos teores de fósforo e nitrogênio e estão associados a degradação das florestas ripárias, podendo explicar a elevada produtividade primária no ponto "ETE" e "Jusante".

Tabela 1. Variáveis físicas e químicas da água; Média e desvio padrão da largura, profundidade e velocidade da correnteza; Média dos teores de matéria seca livre de cinzas e clorofila-a no seston e no perifíton. Bacia Hidrográfica do rio Corumbá, DF.

\begin{tabular}{|c|c|c|c|c|}
\hline Variáveis Físicas e Químicas & "Referência" & "Montante" & “ETE” & "Jusante" \\
\hline Temperatura $\left({ }^{\circ} \mathrm{C}\right)$ & 20,3 & 22,2 & 18,9 & 19,8 \\
\hline Turbidez (NTU) & 6,12 & 3,1 & 8,88 & 6,2 \\
\hline Condutividade Elétrica $\left(\mu \mathrm{S} \mathrm{cm}^{-1}\right)$ & 12,47 & 36,9 & 195,2 & 165,8 \\
\hline $\mathrm{pH}$ & 6,14 & 6,88 & 7,33 & 7,2 \\
\hline Oxigênio Dissolvido $\left(\mathrm{mg} \mathrm{L}^{-1}\right)$ & 8,25 & 8,47 & 8,24 & 3,57 \\
\hline Largura (m) & $3,1 \pm 0,36$ & $4,53 \pm 0,76$ & $8,17 \pm 0,76$ & $10,92 \pm 1,51$ \\
\hline Profundidade (m) & $0,29 \pm 0,11$ & $0,17 \pm 0,08$ & $0,46 \pm 0,18$ & $0,45 \pm 0,16$ \\
\hline Velocidade da Correnteza $\left(\mathrm{m} \mathrm{s}^{-1}\right)$ & $0,57 \pm 0,30$ & $0,53 \pm 0,25$ & $0,67 \pm 0,15$ & $0,23 \pm 0,06$ \\
\hline $\begin{array}{l}\text { Matéria Seca Livre de Cinzas no } \\
\text { Seston }\left(\% \mathrm{~L}^{-1}\right)\end{array}$ & 14,29 & 64,17 & 32,50 & 18,33 \\
\hline $\begin{array}{l}\text { Matéria Seca Livre de Cinzas no } \\
\text { Perifíton }\left(\% \mathrm{~m}^{-2}\right)\end{array}$ & 3,52 & 25,48 & 33,69 & 19,17 \\
\hline $\begin{array}{l}\text { Matéria Orgânica no Sedimento } \\
\text { Depositado }(\%)\end{array}$ & 4,54 & 3,27 & 2,10 & 2,24 \\
\hline$\%$ Pedras e Cascalho $(>2,0 \mathrm{~mm})$ & 93,31 & 89,24 & 69,07 & 84,24 \\
\hline$\%$ Areia $(0,075-2,0 \mathrm{~mm})$ & 6,54 & 10,69 & 29,45 & 15,04 \\
\hline$\%$ Silte e Argila $(<0,075 \mathrm{~mm})$ & 0,15 & 0,06 & 1,48 & 0,73 \\
\hline Clorofila-a no Seston $\left(\mu \mathrm{g} \mathrm{L}^{-1}\right)$ & - & - & 7,69 & 6,59 \\
\hline Clorofila-a no Perifíton $\left(\mathrm{mg} \mathrm{m}^{-2}\right)$ & 0,98 & 9,52 & 51,99 & 17,33 \\
\hline
\end{tabular}

Na granulometria do sedimento depositado nos pontos "ETE" e "Jusante" foi encontrada uma maior proporção das frações mais finas e média no sedimento depositado, enquanto que no "Referência" e no " Montante", foram encontradas maiores porcentagens da granulometria grossa (Tabela 1). Um dos principais impactos que podem ser gerados com o aumento da 
granulometria fina é a simplificação das comunidades que habitam o sedimento pois sua maior quantidade no sedimento pode reduzir a complexidade dos habitats, sua heterogeneidade e estabilidade (Palmer et al., 2000).

Quanto à comunidade bentônica, foram identificados os táxons Diptera (Chironomidae e Simulidae), Coleoptera, Ephemeroptera, Plecoptera, Trichoptera (Hydropsychidae), Odonata, Olighoqueta, Lepidoptera e Mollusca. As larvas de Chironomus (Chironomidae: Diptera) apresentaram maior abundância nos pontos "ETE" e "Jusante", que por sua vez demonstraram uma menor riqueza de táxons em relação aos pontos "Referência" e "Montante" (Tabela 2). A presença de alta densidade de larvas de Chironomus em ambientes aquáticos pode estar associada ao lançamento de efluentes domésticos, corroborando com os estudos de Machado et al. (2015) e Oliveira et al. (2010). Nossos resultados corroboram o potencial deste grupo taxonômico como indicador adequado na avaliação da qualidade da água em riachos tropicais.

No ponto "Montante" o maior número de indivíduos identificados pertence à família Hydropsychidae, e o segundo grupo mais abundante foram as larvas de Chironomus (Tabela 2). De acordo com Barbour et al. (1999), Hydropsychidae é o grupo mais tolerante a poluição dentre aqueles que compõem a ordem Trichoptera. A menor abundância de larvas de Chironomus e a maior riqueza de táxons no ponto "Referência" em relação aos demais, além da presença dos grupos taxonômicos Ephemeroptera, Plecoptera e Trichoptera (desconsiderando o Hydropsychidae), dos resultados obtidos para as variáveis físicas e químicas da água e da menor porcentagem de ocupação antrópica, reforçam a hipótese inicial de que este riacho pode ser considerado o mais íntegro dentre os pontos amostrados.

Tabela 2. Distribuição da abundância relativa (A. R.) e da densidade de organismos bentônicos por metro quadrado (D. ind. $/ \mathrm{m}^{2}$ ) nos táxons identificados nos riachos da Bacia Hidrográfica do rio Corumbá, DF.

\begin{tabular}{|c|c|c|c|c|c|c|c|c|}
\hline \multirow[b]{2}{*}{ Táxons } & \multicolumn{2}{|c|}{ "Referência" } & \multicolumn{2}{|c|}{ "Montante" } & \multicolumn{2}{|c|}{ "ETE" } & \multicolumn{2}{|c|}{ "Jusante" } \\
\hline & $\begin{array}{l}\text { A.R } \\
(\%)\end{array}$ & $\begin{array}{c}\text { D. } \\
\text { ind. } \mathrm{m}^{-2}\end{array}$ & $\begin{array}{l}\text { A.R } \\
(\%)\end{array}$ & $\begin{array}{c}\text { D. } \\
\text { ind. } \mathrm{m}^{-2}\end{array}$ & $\begin{array}{l}\text { A.R } \\
(\%)\end{array}$ & $\begin{array}{c}\text { D. } \\
\text { ind. } \mathrm{m}^{-2}\end{array}$ & $\begin{array}{l}\text { A.R } \\
(\%)\end{array}$ & $\begin{array}{c}\text { D. } \\
\text { ind. } \mathrm{m}^{-2}\end{array}$ \\
\hline \multicolumn{9}{|l|}{ Diptera } \\
\hline Chironomidae & 52,22 & 148 & 32,60 & 416 & 99,95 & 8288 & 99,56 & 2692 \\
\hline Simulidae & - & - & 15,36 & 196 & - & - & - & - \\
\hline Coleoptera & 8,95 & 24 & - & - & - & - & - & - \\
\hline Ephemeroptera & 8,95 & 24 & - & - & - & - & - & - \\
\hline Plecoptera & 1,49 & 4 & - & - & - & - & - & - \\
\hline \multicolumn{9}{|l|}{ Trichoptera } \\
\hline Hydropsychidae & 25,37 & 68 & 47,33 & 604 & - & - & - & - \\
\hline Odonata & - & - & 1,57 & 20 & - & - & - & - \\
\hline Oligoqueta & - & - & 0,94 & 12 & - & - & - & - \\
\hline Lipidoptera & - & - & 2,19 & 28 & - & - & - & - \\
\hline Mollusca & - & - & - & - & 0,05 & 4 & 0,44 & 12 \\
\hline Total de indivíduos (n) & \multicolumn{2}{|c|}{67} & \multicolumn{2}{|c|}{319} & \multicolumn{2}{|c|}{2073} & \multicolumn{2}{|c|}{676} \\
\hline Total de indivíduos $/ \mathrm{m}^{2}$ & \multicolumn{2}{|c|}{268} & \multicolumn{2}{|c|}{1276} & \multicolumn{2}{|c|}{8292} & \multicolumn{2}{|c|}{2704} \\
\hline
\end{tabular}




\section{CONCLUSÃO}

O presente estudo fornece indícios de eutrofização, que pode ocorrer tanto em função da ineficiência das técnicas utilizadas para o tratamento do esgoto, quanto da ocorrência de lançamento clandestino de efluentes não tratados à montante do riacho. Os resultados corroboram com o estudo de Machado et al. (2015) ao observar diferenças significativas na densidade de larvas de Chironomus entre os pontos com presença e ausência de efluentes domésticos parcialmente tratados. Dessa forma, a avaliação rápida da integridade realizada foi capaz de identificar diferenças expressivas no estado de conservação do riacho. Compreender as alterações causadas pelos impactos antrópicos é essencial para promover ações que visem manter e recuperar a integridade dos ecossistemas aquáticos.

\section{AGRADECIMENTOS}

À EMBRAPA Hortaliças e aos moradores da região rural do Gama/DF (que desejam novamente usufruir do riacho que, atualmente, não apresenta condições adequadas de potabilidade) por permitirem o acesso às suas propriedades para realização das coletas. À Universidade Católica de Brasília pelo empréstimo dos materiais necessários para a realização das coletas. À Universidade de Brasília pelo empréstimo dos sensores de medição analisados.

\section{REFERÊNCIAS}

ALLAN, J. D.; CASTILLO, M. M. Stream ecology: structure and function of running waters. 2nd. ed. [s.1.]: Springer, 2007. p. 436.

ARAUJO, M. C.; OLIVEIRA, M. B. M. Monitoramento da qualidade das águas de um riacho da Universidade Federal de Pernambuco, Brasil. Revista Ambiente \& Água, v. 8, n. 3, p. 247-257, 2013. http://dx.doi.org/10.4136/ambi-agua.1192

BARBOUR, M. T.; GERRITSEN, J.; SNYDER, B. D.; STRIBLING, J. B. Rapid bioassessment protocols for use in streams and wade able rivers: periphyton, benthic macroinvertebrates and fish. 2nd ed. Washington, DC: USEPA, 1999.

COMPANHIA DE SANEAMENTO AMBIENTAL DO DISTRITO FEDERAL - CAESB. Website. Disponível em: http://www.caesb.df.gov.br/. Acesso em: 15 dez. 2015.

CALliSTO, M.; FERREIRA, W. R.; MORENO, P.; GOULART, M.; PETRUCIO, M. Aplicação de um protocolo de avaliação rápida da diversidade de hábitats em atividades de ensino e pesquisa. Acta Limnologica Brasiliensia, v. 34, p. 91-97, 2002.

DODDS, W. K. Eutrophication and trophic state in rivers and streams. American Society of Limnology and Oceanography, v. 51, n. 1, p. 671-680, 2006. http://dx.doi.org/10.4319/lo.2006.51.1_part_2.0671

FONSECA, B. M.; MENDONÇA-GALVÃO L.; PADOVESI-FONSECA, C.; ABREU L. M.; FERNANDES, A. C. Nutrient baselines of cerrado low-order streams: comparing natural and impacted sites in central Brazil. Environmental monitoring and Assessment, v. 186, n. 1, p. 19-33, 2014. http://dx.doi.org/10.1007/s10661-013-3351-8 
MACHADO, N. G.; NASSARDEN, D. C. S.; SANTOS, F.; BOAVENTURA, I. C. G.; PERRIER, G.; SOUZA, F. S. C.; et al. Chironomus larvae (Chironomidae: Diptera) as water quality indicators along an environmental gradient in a neotropical urban stream. Revista Ambiente \& Água, v. 10, n. 2, 2015. http://dx.doi.org/10.4136/ambiagua. 1533

MENDONÇA-GALVÃO, L. et al. Águas do cerrado do Distrito Federal: biodiversidade, integridade e conservação. In: FAGG, C. W.; MUNHOZ, C. B. R.; SOUSA-SILVA, J. (Eds.). Conservação de áreas de preservação permanente do cerrado. Brasília-DF: CRAD, 2011. p. 21-46.

MERRITT, R. W.; CUMMINS, K. W.; BERG, M. (Eds.). An introduction to the aquatic insects of North America. 4th ed. Dubuque: Kendall Hunt Publishing, 2008. 1158 p.

OLIVEIRA, V.; MARTINS, R.; ALVES, R. Evaluation of water quality of an urban stream in southeastern Brazil using Chironomidae Larvae (Insecta: Diptera). Neotropical Entomology, v. 39, n. 6, p. 873-878, 2010. http://dx.doi.org/10.1590/S1519566X2010000600004

PALMER, M. A.; COVICH, A. P.; LAKE, S.; BIRO, P.; BROOKS, J. J.; COLE, J. et al.Linkages between aquatic sediment biota and life above sediments as potential drivers of biodiversity and ecological process. Bioscience, v. 50, p. 1062-1075, 2000. 10.1641/0006-3568(2000)050[1062:LBASBA]2.0.CO;2

TUNDISI, J. G. Novas perspectivas para a gestão de recursos hídricos. Revista USP, v. 70, p. 24-35, 2006. 